\title{
Real-Time Temperature Measurement Using Infrared Thermography Camera and Effects on Tensile Strength and Microhardness of Hot Wire Plasma Arc Welding
}

\author{
Nirut Naksuk *, Jiradech Nakngoenthong, Waravut Printrakoon and Rattanapon Yuttawiriya \\ National Metal and Materials Technology Center (MTEC), National Science and Technology Development \\ Agency, 114 Thailand Science Park, Khlong Luang, Pathum Thani 12120, Thailand; jiradecn@mtec.or.th (J.N.); \\ waravutp@mtec.or.th (W.P.); rattanapon.yut@mtec.or.th (R.Y.) \\ * Correspondence: nirutn@mtec.or.th; Tel.: +66-2564-6500 (ext. 4149)
}

Received: 8 July 2020; Accepted: 26 July 2020; Published: 3 August 2020

\begin{abstract}
The hot wire plasma arc welding process, a hybrid process between the plasma arc welding (PAW) process and hot wire process, is used to weld 316 stainless steel sheets, in which the temperature generated during welding is recorded in real time with a high-speed infrared thermography camera. Therefore, this research studies the factors in the hot wire process, of which there are two: (1) wire feed rate and (2) wire current; this study investigated the tensile strength, microhardness, and relationship of cooling rate per tensile strength and microhardness. The study found that the hot wire current plays an important role in cooling rates and tensile strength. The temperature results from high-speed infrared thermography camera show that the maximum welding temperature is around $1300^{\circ} \mathrm{C}$. The weld pool has a temperature between 900 and $1300{ }^{\circ} \mathrm{C}$ and the temperature profile of the weld pool will look like an " $\mathrm{M}$ " shaped, which is caused by the hot wire process. Finally, the appropriate hot wire parameters are $1.5 \mathrm{~m} / \mathrm{min}$ for wire feed rate and $40 \mathrm{~A}$ for wire current, which will give the workpiece cooling rate of $800-500{ }^{\circ} \mathrm{C}$ as $13.42{ }^{\circ} \mathrm{C} / \mathrm{s}$, tensile strength of $610.95 \mathrm{MPa}$, and the average Vickers microhardness of $195 \mathrm{HV}$.
\end{abstract}

Keywords: real time; infrared thermography; camera; tensile strength; microhardness; plasma arc welding; hot wire

\section{Introduction}

Hot wire plasma arc welding is relatively a new welding process, a hybrid process between the plasma arc welding (PAW) process and the hot wire process. The hot wire process can be used as a hybrid with other welding processes such as gas tungsten arc welding (GTAW) process or laser welding process [1-3]. The basic principle of the hot wire process is to heat the consumable filler wire by a separate power source until close to the melting point and feed to the weld pool [4]. There are many advantages over the cold wire process, mainly high deposition rates $[5,6]$, which will assist to increase welding speed and productivity. The work of [7] has been conducted to study mechanical properties to compare the results between the use of hot wire and cold wire of GTAW. The results showed that the mechanical properties obtained were not significantly different between the use of hot wire and cold wire. In general, hot wire process parameters (such as wire current, wire feed rate, wire feed angle, wire size, wire contact length, gas shield) have a significant effect on the quality of the obtained workpiece [8-10]. The selection of inappropriate parameters can result in weld defects [11]. Therefore, choosing the appropriate parameters will increase the mechanical properties and achieve quality welding workpieces. The optimization of hot wire laser welding parameters has been studied [12] 
based on ensemble metamodels and non-dominated sorting genetic algorithm. This research studied the three parameters, that is, laser power, welding speed, and hot wire current. The results showed that the optimal process parameters gave results consistent with the experiment. Although research articles related to the hot wire process are available [13-15], research on hot wire plasma arc welding is limited. Therefore, the study of the basic parameters of the hot wire process is interesting to obtain good mechanical properties of the welding workpiece. Recently, cameras have been widely used to study the real-time welding process [16-18], which are non-contact measure and give results with high accuracy and precision. The information obtained from the camera gives insight into various forms of weld results such as temperature, geometric shape, and defects. The temperature data recorded from the camera can be used to calculate the cooling rates that occur in the range of $800-500{ }^{\circ} \mathrm{C}$, which is a material phase transformation that affects the microstructure and mechanical properties. The effects of cooling rate in a super duplex stainless steel on pulsed GTAW welding have been studied [19] using three process parameters (heat input, wire feed rate, wire feed technique). The results found that the heat input plays an important role in the cooling rate, which affects microstructure in the heat-affected zone (HAZ) and weld zone. From the literature review [20-22], we found that the main factors affecting the cooling rate were heat input, type of material, and the thickness of the material.

This paper presents the hot wire plasma arc welding process using a high-speed infrared thermography camera to measure the temperature in real time. The resulting temperature profile allows to calculate the cooling rate of the workpiece, which will obtain the relationship between the cooling rate and the mechanical properties (tensile strength, microhardness). Furthermore, the appropriate parameters for the hot wire plasma arc welding process are obtained that allow the welding workpiece to have tensile strength and microhardness within the specified standards.

\section{Materials and Methods}

The material used in this research is a stainless steel sheet in accordance with AISI 316 (equivalent to DIN 1.4401 and JIS SUS 316), which has a chemical composition measured from the machine brand, Thermo Scientific, model: ARL 3460 Metals Analyzer by optical emission spectrometry (OES) compared with the standard chemical composition [23] and the mechanical property values as in Tables 1 and 2, respectively.

Table 1. Chemical composition of AISI 316 by optical emission spectrometry.

\begin{tabular}{ccc}
\hline Elements & Standard $(\% w / w)$ & Measured $(\% w / w)$ \\
\hline C (Max) & 0.08 & 0.019 \\
Cr & $16-18$ & 15.697 \\
Fe & $61.8-72$ & 70.354 \\
Mn (Max) & 2.0 & 1.377 \\
Mo & $2.0-3.0$ & 2.140 \\
Ni & $10-14$ & 10.039 \\
P (Max) & 0.045 & 0.029 \\
Si (Max) & 1.0 & 0.341 \\
S (Max) & 0.03 & 0.004 \\
\hline
\end{tabular}

Table 2. The mechanical property of AISI 316.

\begin{tabular}{ccc}
\hline Mechanical Properties & Standard Value & Measured Value \\
\hline Hardness, Vickers & $146 \mathrm{HV}$ & $197.96 \mathrm{HV}$ \\
Ultimate Tension Strength & $580 \mathrm{MPa}$ & $598.52 \mathrm{MPa}$ \\
Yield Strength & $290 \mathrm{MPa}$ & $360.76 \mathrm{MPa}$ \\
Elongation at Break & $30-50 \%$ & $35.36 \%$ \\
Modulus of Elasticity & $193 \mathrm{GPa}$ & $198.42 \mathrm{GPa}$ \\
\hline
\end{tabular}


The workpiece used was $100 \mathrm{~mm}$ in width, $150 \mathrm{~mm}$ in length, and $3 \mathrm{~mm}$ in thickness using two sheets per experiment and using a closed square butt joint. The workpiece will be clamped by jigs to prepare for hot wire plasma arc welding by machine brand, Cebora, model: EVO 450T (Bologna, Italy), which is used as the current source. The plasma welding controller from the machine brand, Cebora, model: digital Console PW30 (Bologna, Italy), was employed, which is used for controlling various parameters for plasma welding. The hot wire machine used the brand, MAC, model: Power Assist IV-642 (Osaka, Japan), with a wire feed system to the welding torch, which is attached to the ABB robotic arm, model: IRB4400 (Västerås, Sweden) used for controlling the hot wire plasma arc welding path, as shown in Figure 1. The hot wire plasma arc welding parameters used in this research are shown in Table 3. The welding process starts from the right-hand side of the workpiece and ends at the left-hand side. Here, the plasma torch was at the front, while the hot wire was feed behind the plasma welding torch, with a total welding distance of $130 \mathrm{~mm}$.

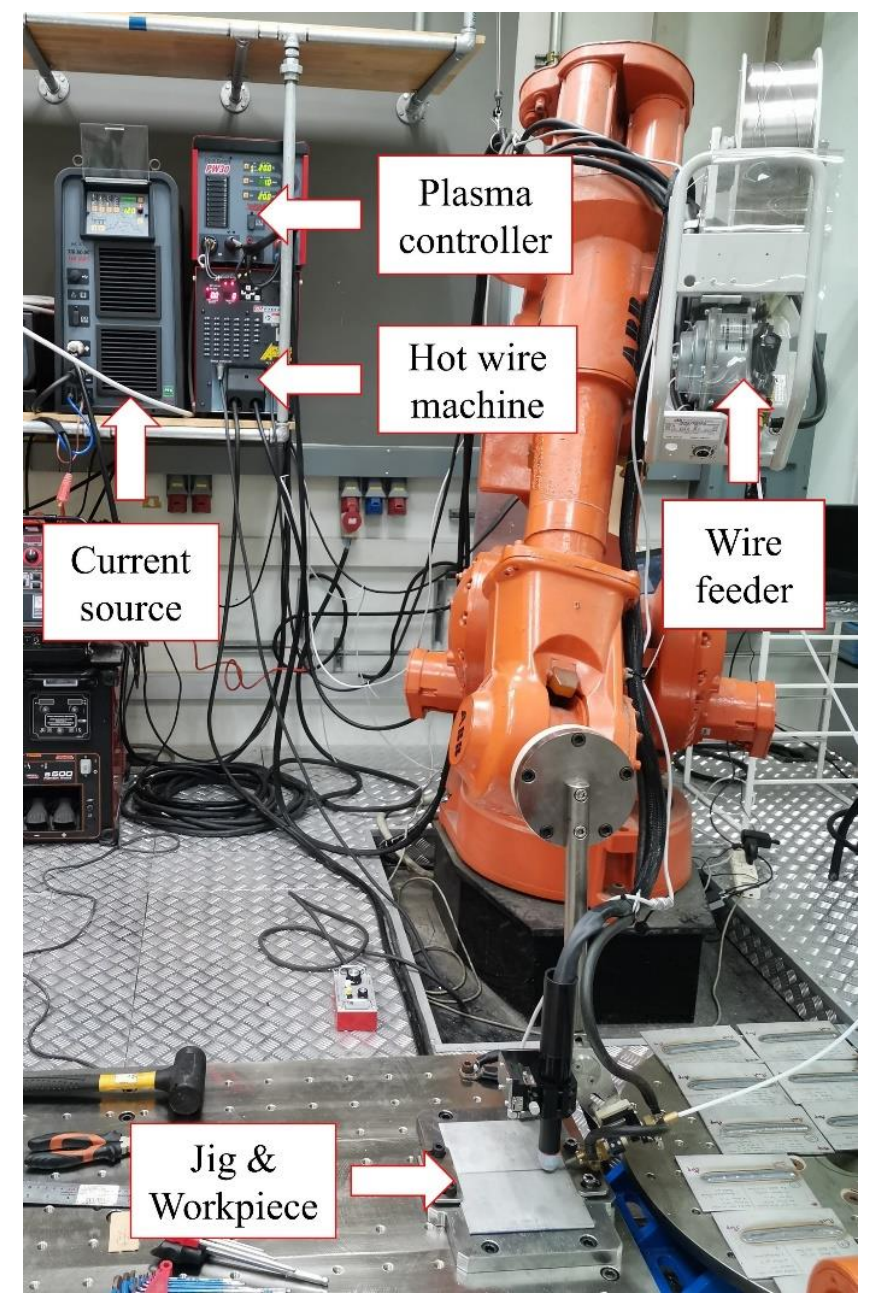

Figure 1. The hot wire plasma arc welding system.

For real-time temperature measurement during hot wire plasma arc welding, the high-speed infrared thermography camera brand, Infratec, model: ImageIR 8300 (Dresden, Germany), was used, with a temperature measurement accuracy of $\pm 1 \%$. The principle of temperature measurement was that all objects with temperatures above zero kelvin $\left(-273.15{ }^{\circ} \mathrm{C}\right)$ emit infrared radiation that is invisible to the human eye. The camera with an Indium antimonide (InSb) sensor will measure the mediumwave infrared (MWIR) radiation, wavelength between 2 and $5 \mu \mathrm{m}$. The conversion of infrared radiation detected by sensors into temperature units, based on Planck's law and Stefan-Boltzmann's law according to the behavior of infrared pyrometer. Infrared emission of the object to be measured may 
be more or less depending on the wavelength. The parameters such as material composition, surface roughness, and measurement angle have some influence on wavelength [24]. Thus, the installation of the camera must control the environment to be constant throughout the experiment to not affect the results. This camera is equipped with an ImageIR ${ }^{\circledR}$ standard lens with a focal length of $25 \mathrm{~mm}$ and a motorized filter wheel with spectral filters. This camera will be installed at a distance of $80 \mathrm{~cm}$ from the welding workpiece. The camera mounting point will be on the side of the workpiece so that the temperature can be seen throughout the welding length, as shown in Figure 2. This research sets the camera to record the temperature every $0.5 \mathrm{~s}(f=2 \mathrm{~Hz})$, using the recording time of $240 \mathrm{~s}$. Using a high-speed infrared thermography camera will make it possible to be aware of the temperature occurring throughout the welding process, and to know the temperature in every position such as weldment position, HAZ, and base material, including the temperature that occurs on hot wire feed to the weld pool, from the beginning to the cooling rate after the welding is done. Although the plasma light is brighter, the infrared radiation is always emitted, which passes through the spectral filters into the camera's sensor. This camera uses an Indium antimonide (InSb) sensor that is narrow-gap sensitive at wavelengths between 2 and $5 \mu \mathrm{m}$. Therefore, other wavelengths will not affect the measurement of the temperature.

Table 3. Parameters for hot wire plasma arc welding.

\begin{tabular}{cc}
\hline Parameters & Value \\
\hline Current of arc & $120 \mathrm{~A}$ \\
Current of pilot arc & $20 \mathrm{~A}$ \\
Flow of gas plasma & $0.5 \mathrm{~L} / \mathrm{min}$ \\
Flow of gas shield & $20 \mathrm{~L} / \mathrm{min}$ \\
Plasma and shield gas & Argon \\
Nozzle tip diameter & $2.5 \mathrm{~mm}$ \\
Torch angle & $90 \mathrm{degree}$ \\
Arc distance & $6 \mathrm{~mm}$ \\
Welding speed & $180 \mathrm{~mm} / \mathrm{min}$ \\
Wire diameter & $1.2 \mathrm{~mm}$ \\
Wire type & $316 \mathrm{LSi}$ \\
Wire feed angle & $40 \mathrm{degree}$ \\
Room temperature & $24^{\circ} \mathrm{C}$ \\
\hline
\end{tabular}

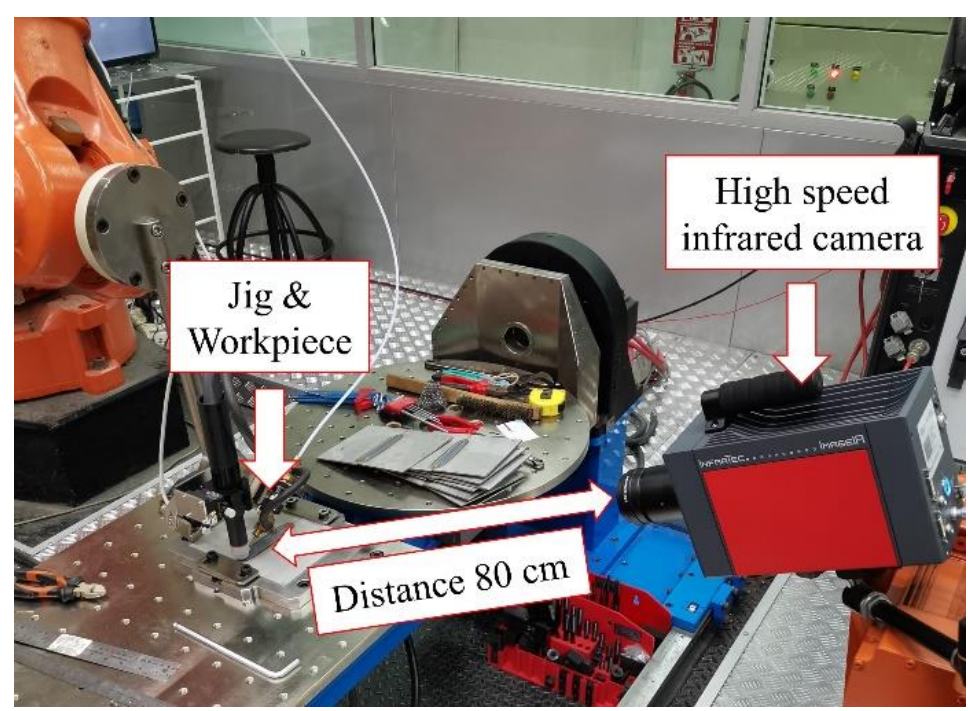

Figure 2. Installed high-speed infrared thermography camera.

The cooling rate at the temperature range $800-500{ }^{\circ} \mathrm{C}$ will be studied because the temperature range is the material phase transformation, which has a significant impact on the properties of the 
workpiece. The formula for calculating the cooling rate range $800-500{ }^{\circ} \mathrm{C}$ is calculated from a simple equation as shown in Equation (1):

$$
\text { Cooling rate } e_{800-500^{\circ} \mathrm{C}}=\frac{\Delta \text { Temp }_{800-500^{\circ} \mathrm{C}}}{\Delta \text { time }_{800-500^{\circ} \mathrm{C}}}
$$

where $\Delta \operatorname{Temp}_{800-500^{\circ} \mathrm{C}}=$ the temperature difference at $800{ }^{\circ} \mathrm{C}$ and $500{ }^{\circ} \mathrm{C}, \Delta$ time $_{800-500^{\circ} \mathrm{C}}=$ the time difference at $800{ }^{\circ} \mathrm{C}$ and $500{ }^{\circ} \mathrm{C}$.

Each workpiece uses three positions to measure the resulting temperature, as shown in Figure 3. Here, position 1 (P1) is the center of the weldment; position 2 (P2) is at a distance of $5 \mathrm{~mm}$ away from the center of the weldment, which is the area of the HAZ; and position 3 (P3) is at a distance of $10 \mathrm{~mm}$ from the center of the weldment, which is the base material. Besides, the temperature of the hot wire at a height of $7.5 \mathrm{~mm}$ from the workpiece surface is measured.

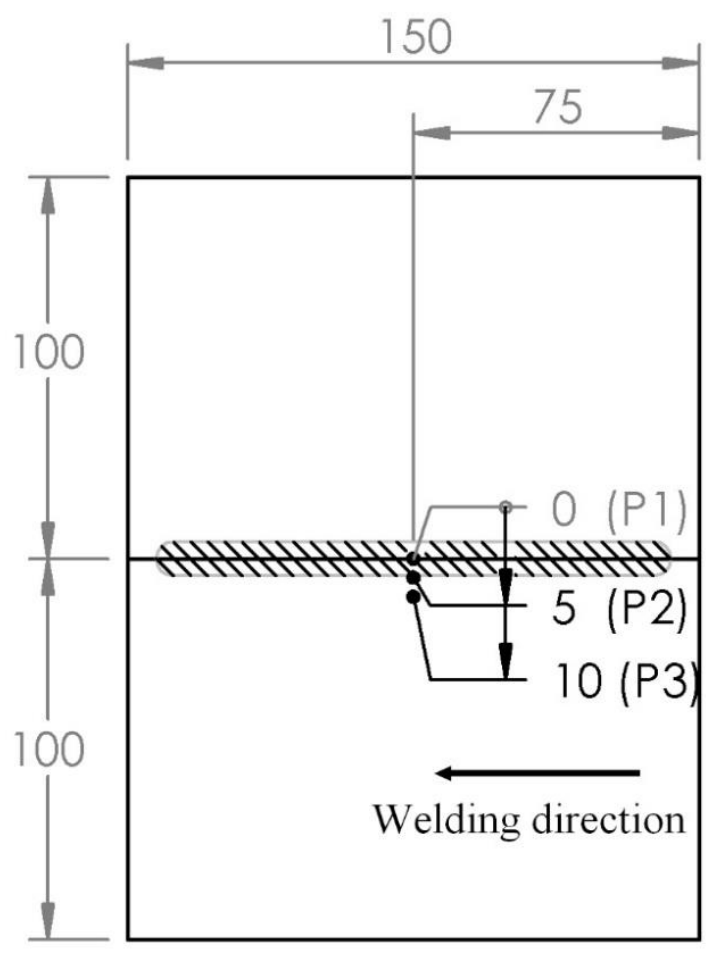

Dimensional unit in millimeter

Figure 3. Position for measuring temperature.

Once the installation of the hot wire plasma arc welding system is finished, the next step will be to design the experiment, in which this research will use the design of a full factorial experiment. The factors used in this study will be the factors of the hot wire process, which has two factors, wire feed rate and wire current, where each factor is assigned to have two levels caused by the trial and error of the preliminary study, whereby such parameters and ranges do not cause defect workpieces and obtain complete welds, such as no sputtering during welding, good penetration, no cracking of welds, uniform hot wire during welding, and the experimental design table, as shown in Tables 4 and 5, respectively.

Table 4. Determining the level of factors used in the experiment.

\begin{tabular}{ccccc}
\hline Factors & Symbol & Unit & Low Level & High Level \\
\hline Wire feed rate & $\mathrm{A}$ & $\mathrm{m} / \mathrm{min}$ & 1.5 & 1.7 \\
Wire current & $\mathrm{B}$ & $\mathrm{A}$ & 30 & 40 \\
\hline
\end{tabular}


Table 5. Full factorial experimental design table.

\begin{tabular}{ccc}
\hline Run Order & $\begin{array}{c}\text { A } \\
\text { (Wire Feed Rate) } \\
\text { (m/min) }\end{array}$ & $\begin{array}{c}\text { B } \\
\text { (Wire Current) } \\
\text { (A) }\end{array}$ \\
\hline 1 & 1.7 & 40 \\
2 & 1.7 & 30 \\
3 & 1.5 & 40 \\
4 & 1.5 & 30 \\
\hline
\end{tabular}

When the hot wire plasma arc welding process is finished according to the experimental design. The workpieces in each experiment are divided into three parts, as shown in Figure 4. The parts number 1 and number 3 of each welded workpiece will be tested for ultimate tensile strength in accordance with ASTM-E8 to find the average ultimate tensile strength value and the dimension of the tensile test workpiece, as shown in Figure 5. Tensile testing uses the machine brand, Instron, model: 8801 (Norwood, MA, USA), equipped with a strain gauge to find an elongation at break.

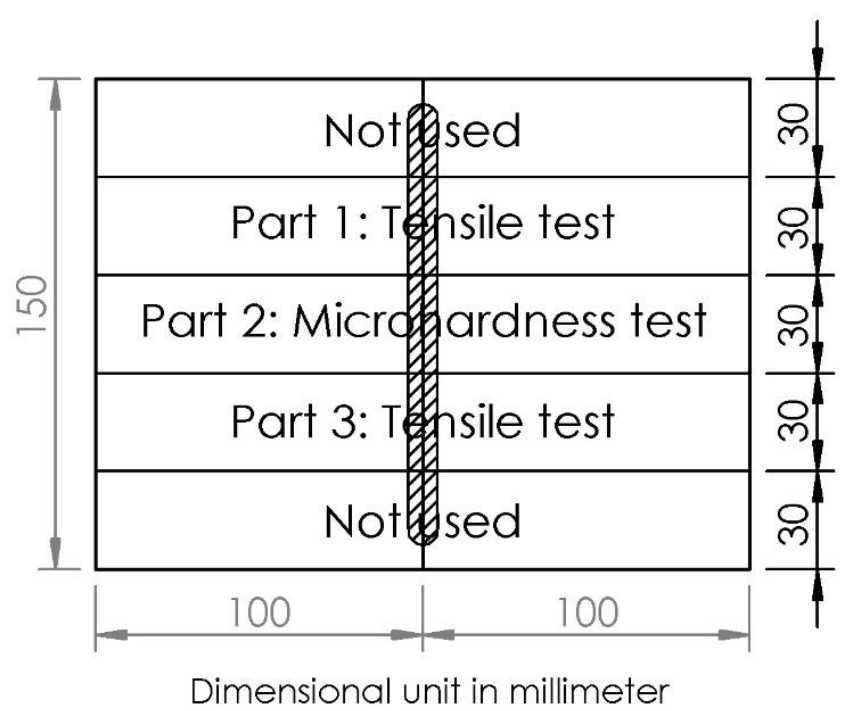

Figure 4. Separation of welded workpieces.

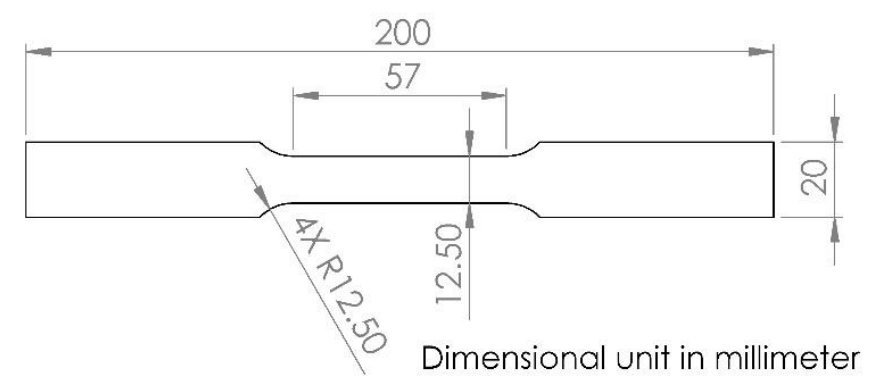

Figure 5. The dimension of the test workpiece in accordance with ASTM-E8.

Part number 2 of each welded workpiece after going through the grinding and polishing processes will be tested for Vickers microhardness by machine brand, Anton-Paar, model: MHT-10 (Graz, Austria). The parameters used are $200 \mathrm{~g}$ of testing force or HV0.2; time of withstanding the load of $15 \mathrm{~s}$; loading speed of $25 \mathrm{~g} / \mathrm{s}$, which will test the microhardness at the center of the cross-sectional area (measured at a distance below the surface about $1.5 \mathrm{~mm}$ ); a total of 15 points; and two times per point 
to find the average, as shown in Figure 6. The results will be displayed in a graph that will show the microhardness value in each position.

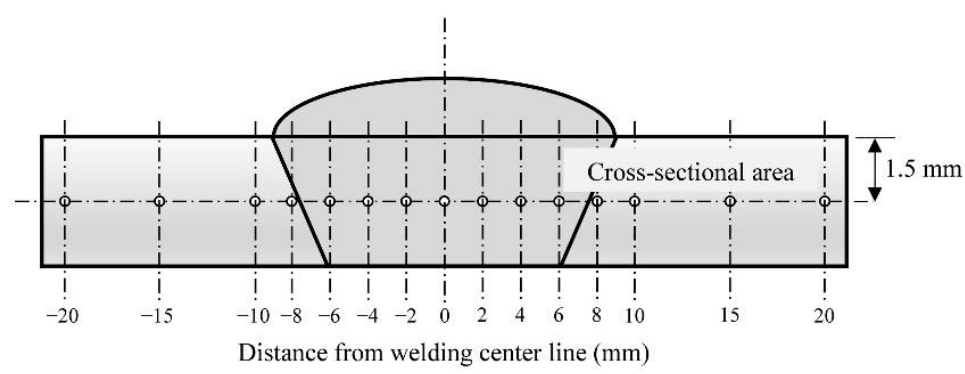

Figure 6. Position for measuring Vickers microhardness.

\section{Results and Discussion}

The program used for high-speed infrared thermography camera for temperature recording and data retrieval was the IRBIS ${ }^{\circledR} 3.1$ Professional program. Figure 7 shows an example of an image captured from a high-speed infrared thermography camera. Each pixel of the image can show the resulting temperature and, therefore, allows knowing the exact location of the temperature. Real-time temperature measurement results using a high-speed infrared thermography camera according to the design of the experimental design could be graphed as shown in Figures 8-11, which are shown, at position 1 (position of weldment), position 2 (position of HAZ), and position 3 (position of base material), to have a graph in the shape like an " $\mathrm{M}$ ". Position 1 has the highest measured temperature of around $1300{ }^{\circ} \mathrm{C}$ and a minimum of about $900{ }^{\circ} \mathrm{C}$. It was shown that the weld pool will have a temperature between 900 and $1300^{\circ} \mathrm{C}$ and then gradually cool down. The occurrence of the graph in the shape like an " $\mathrm{M}$ " owing to the area in front of the weld pool has the area of plasma charge that will cause the workpiece to form a keyhole and this area has the highest temperature, as shown in the graph. Behind the plasma area, caused by the hot wire feeding, causing the temperature to decrease and the tail of the weld pool, the temperature will drop slightly close to the temperature of the plasma area, as shown in Figure 12. Therefore, using a high-speed infrared thermography camera to record the real-time temperature will result in the graph in the shape of an " $\mathrm{M}$ ". Whereas, if the recording frequency is not high or using a thermocouple or if the hot wire is not fed, the " $\mathrm{M}$ " graph will not be produced. The weldment position will have a maximum temperature of about $1300{ }^{\circ} \mathrm{C} \mathrm{higher}$ than the HAZ position, which has a maximum temperature of about $1000^{\circ} \mathrm{C}$, higher than the base material position, which has a maximum temperature of about $700{ }^{\circ} \mathrm{C}$, respectively. The temperature decreases in this order owing to the increasing distance from the center of the weld, in which the highest temperature corresponds to Figure 13. For peak temperature at different distances from the welding center line, as shown in Figure 13, we found that the resulting graph has very little temperature differences owing to the same type and size of material used, even when using different parameters of welding. The maximum temperature at the weldment position of run order 1 is $1324.64{ }^{\circ} \mathrm{C}$, run order 2 is $1324.67{ }^{\circ} \mathrm{C}$, run order 3 is $1324.69^{\circ} \mathrm{C}$, and run order 4 is $1324.62{ }^{\circ} \mathrm{C}$. 


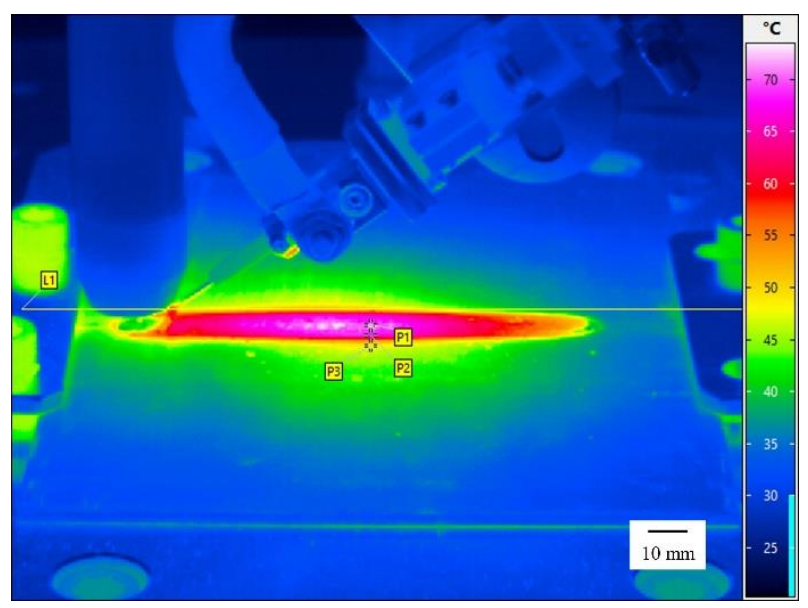

Figure 7. The captured image from a high-speed infrared thermography camera.

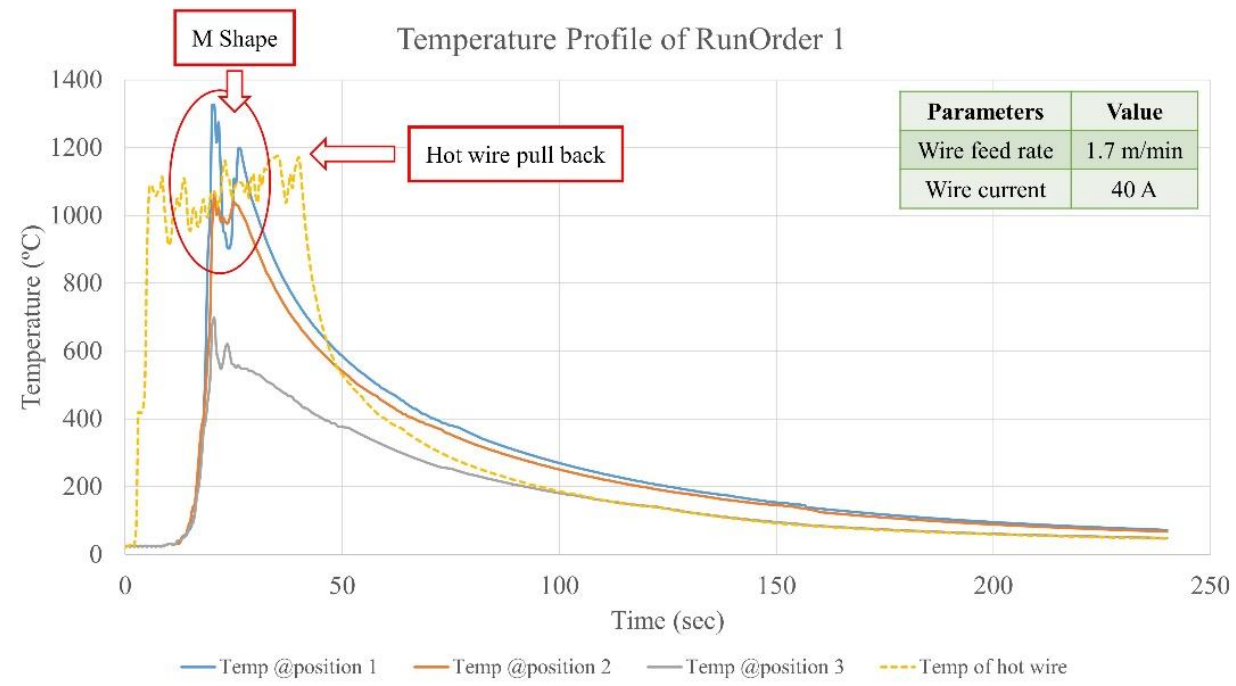

Figure 8. The temperature profile of run order 1.

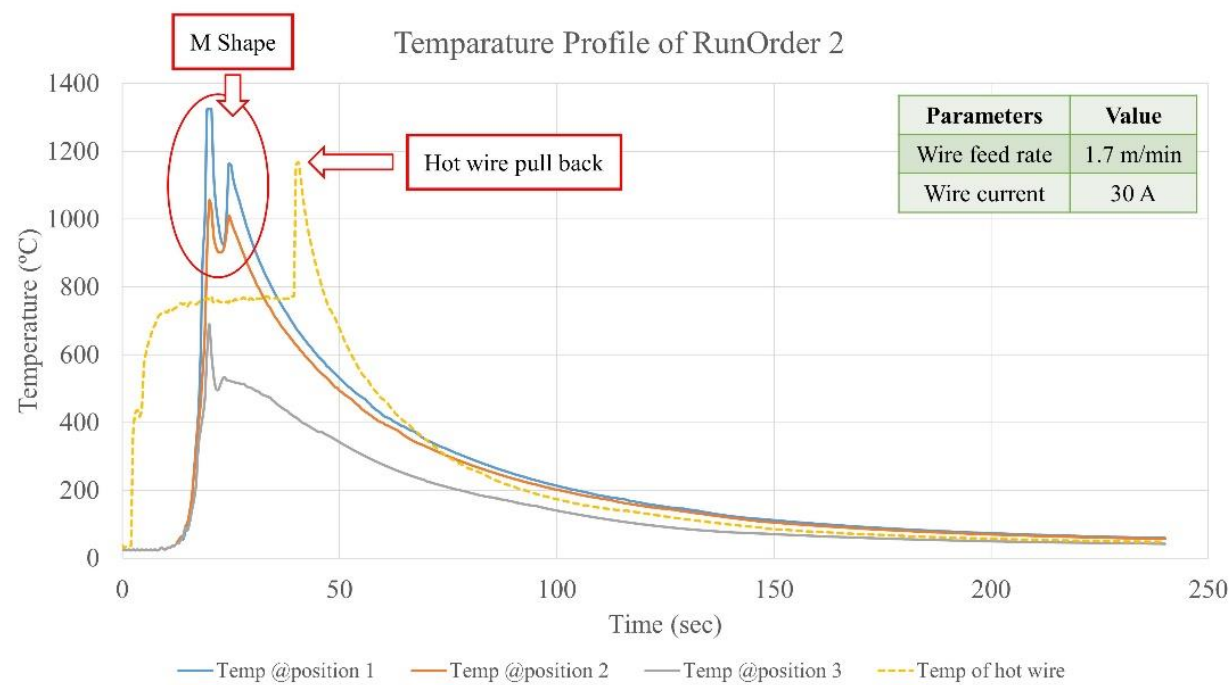

Figure 9. The temperature profile of run order 2. 


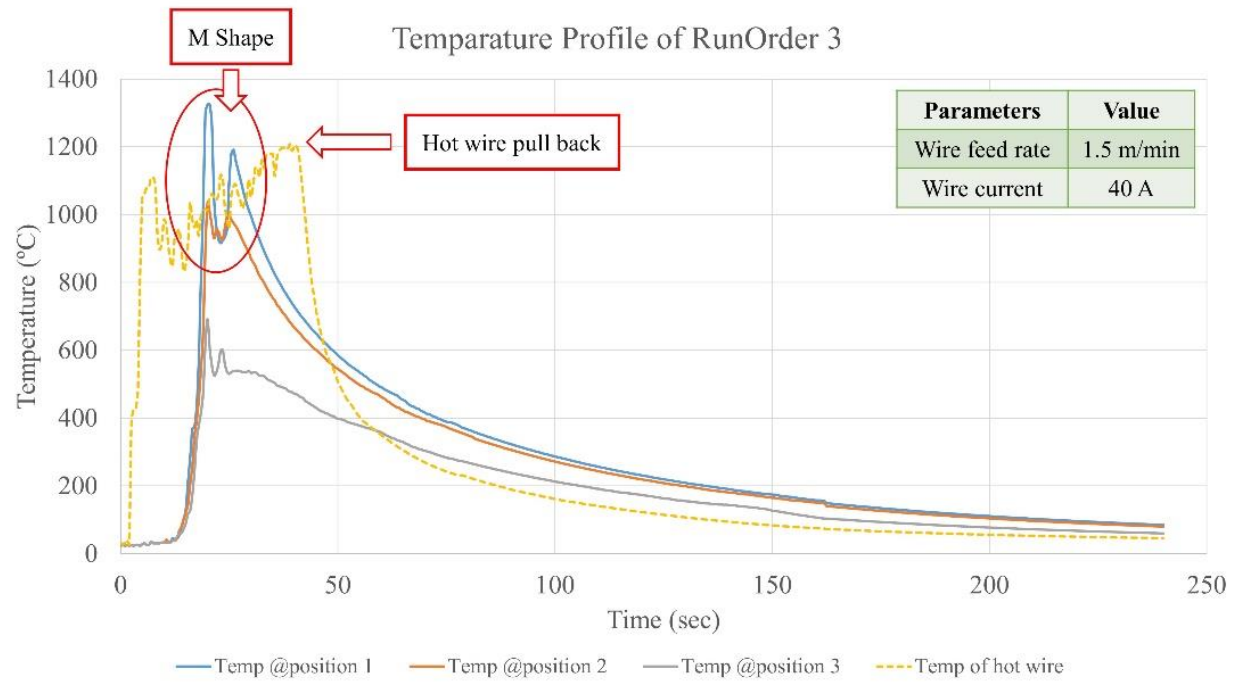

Figure 10. The temperature profile of run order 3.

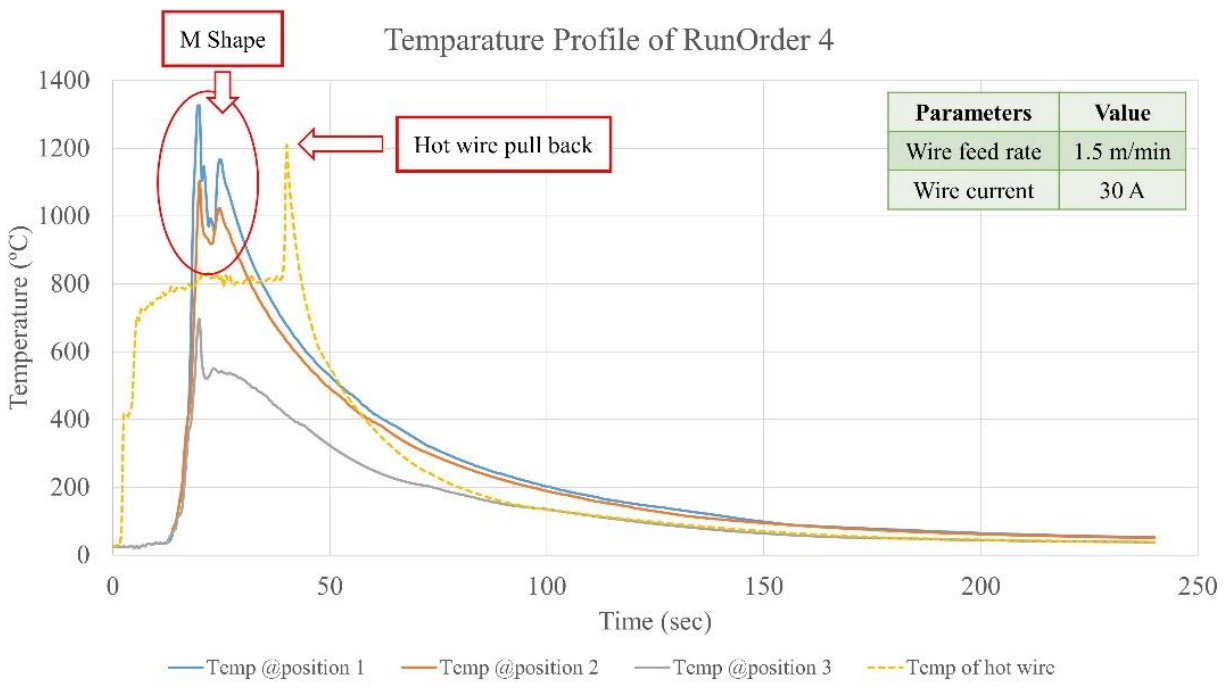

Figure 11. The temperature profile of run order 4.

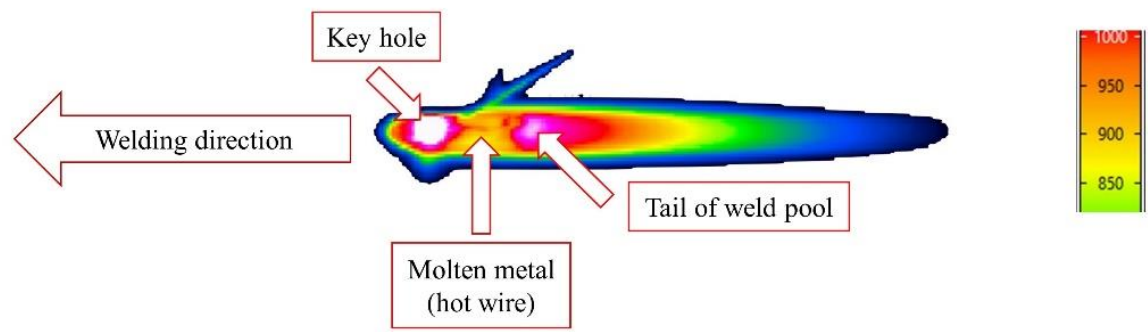

Figure 12. The characteristics of the weld pool results in an M-shaped graph. 


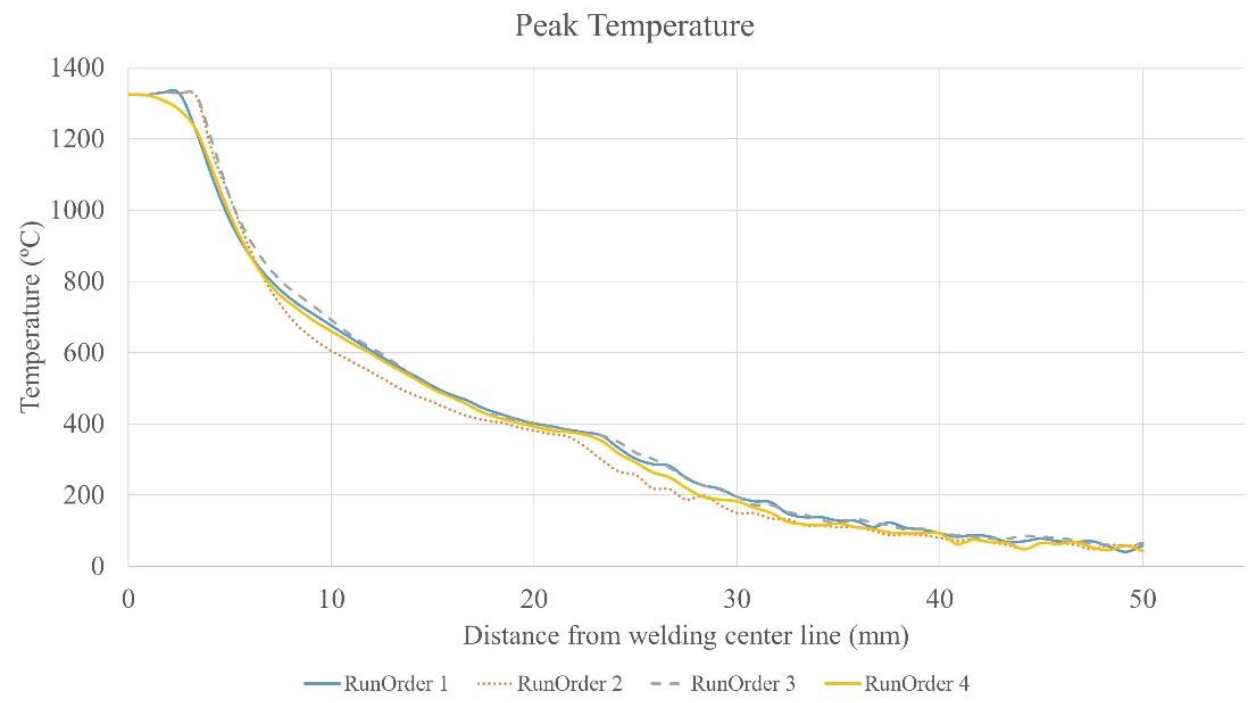

Figure 13. Peak temperature by the distance of the workpiece.

In the graph temperature of the hot wire from Figures 9 and 11, which use hot wire current at $30 \mathrm{~A}$, the hot wire has an average temperature of about $800{ }^{\circ} \mathrm{C}$ throughout the welding process, and the final position when the hot wire is pulled back, as shown in Figure 14, at the tip of the hot wire, will have a temperature of around $1200{ }^{\circ} \mathrm{C}$. It was found that the hot wire during the welding process is still lower than the weld pool, resulting in the hot wire possibly not melting homogeneously with the workpiece, resulting in the workpiece having lower strength according to the tensile strength results obtained from Table 7. In Figures 8 and 10, which use a hot wire current at $40 \mathrm{~A}$, the hot wire has an average temperature of about $1000^{\circ} \mathrm{C}$ throughout the welding process, and the final position when the hot wire is pulled back at the tip of the hot wire will have the temperature around $1200^{\circ} \mathrm{C}$. During the welding process, the hot wire has the temperature close to the weld pool, causing the hot wire to melt homogeneously with the workpiece, resulting in the workpiece being stronger, such as in the results obtained from Table 7 . Therefore, if the workpiece needs to be strong as per the standards, it is necessary to control the hot wire current so that the hot wire has an average temperature during welding around $900-1300{ }^{\circ} \mathrm{C}$ to make the workpiece as strong as possible.
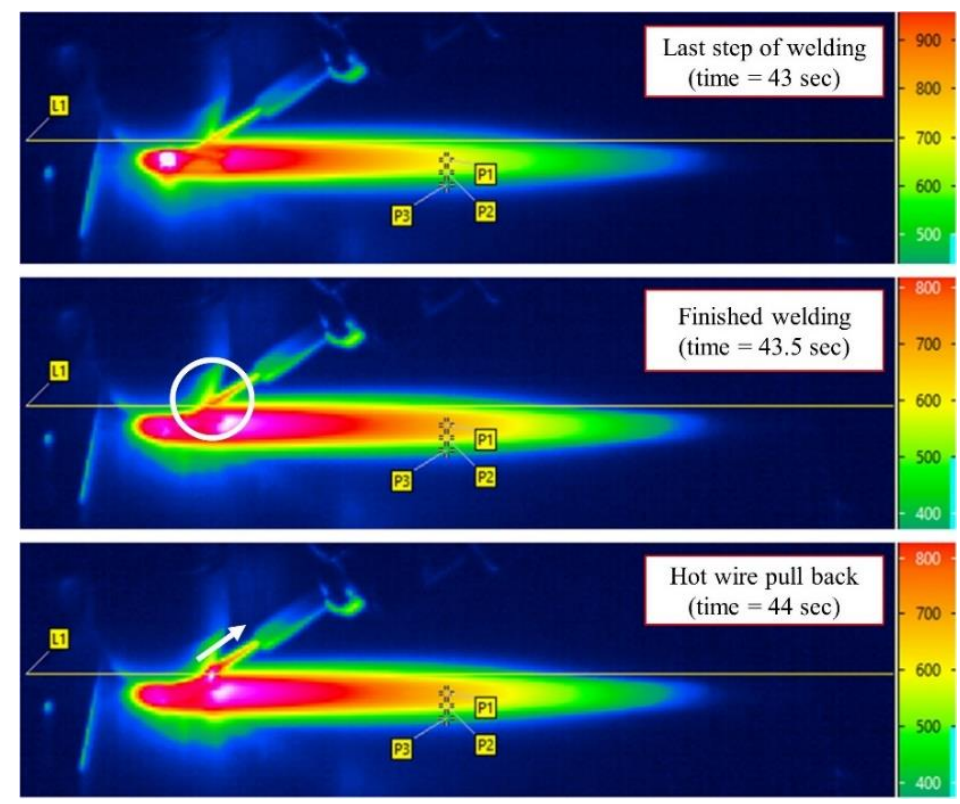

Figure 14. The captured image while the hot wire pulls back. 
From the recorded temperature, the cooling rate can be calculated according to Equation (1); the values used to calculate the cooling rate are shown in Table 6, which found that the cooling rate of $800-500{ }^{\circ} \mathrm{C}$ is between 13.42 and $17.31^{\circ} \mathrm{C} / \mathrm{s}$. Here, position 1 (position of weldment) has a slightly lower cooling rate than position 2 (position of HAZ) in the same workpiece. This is because position 1 has a higher temperature than position 2. Moreover, it was found that the parameters of the hot wire process affect the cooling rate. If the wire current increased, the cooling rate tends to be slower owing to the hot wire temperature.

Table 6. Cooling rate calculation at position 1 and position 2.

\begin{tabular}{ccccccc}
\hline Run Order & Position & $\begin{array}{c}\text { Temperature } \\
\mathbf{0 8 0 0}{ }^{\circ} \mathbf{C} \\
\left({ }^{\circ} \mathbf{C}\right)\end{array}$ & $\begin{array}{c}\text { Temperature } \\
@ \mathbf{5 0 0}{ }^{\circ} \mathbf{C} \\
\left({ }^{\circ} \mathbf{C}\right)\end{array}$ & $\begin{array}{c}\text { Time } \\
\text { @800 } \\
(\mathbf{s})\end{array}$ & $\begin{array}{c}\text { Time } \\
\text { @500 }{ }^{\circ} \mathbf{C} \\
(\mathbf{s})\end{array}$ & $\begin{array}{c}\text { Cooling } \\
\text { Rate } \\
\left({ }^{\circ} \mathbf{C} / \mathbf{s}\right)\end{array}$ \\
\hline 1 & 1 & 810.62 & 497.88 & 36.5 & 58.5 & 14.22 \\
1 & 2 & 809.49 & 497.39 & 33.5 & 54.0 & 15.22 \\
2 & 1 & 796.04 & 495.32 & 34.5 & 53.0 & 16.26 \\
2 & 2 & 804.68 & 494.07 & 31.0 & 50.0 & 16.35 \\
3 & 1 & 800.79 & 498.91 & 36.5 & 59.0 & 13.42 \\
3 & 2 & 809.94 & 497.66 & 32.5 & 55.0 & 13.88 \\
4 & 1 & 810.62 & 497.77 & 34.0 & 52.5 & 16.91 \\
4 & 2 & 809.32 & 497.77 & 31.5 & 49.5 & 17.31 \\
\hline
\end{tabular}

The tensile test results found that run order 3 gave the best results, followed by run order 1, 2, and 4 respectively. Run order 3 and 1 gave the ultimate tensile strength, yield strength, and elongation close to the reference workpiece, which shows that the parameters of run order 3 and 1 are suitable for use. Run order 4 gave the least value, by visual inspection of a broken workpiece, it was found that the fracture was in the position of the workpiece's joint (center of the welds). The breakage characteristics are brittle, resulting in lower ultimate tensile strength, yield strength, and elongation compared with other workpieces, where other workpieces fracture at the base material near the HAZ. The results of the tensile strength given in Table 7 show the consistency of the hot wire parameters, the temperature of the hot wire, and the cooling rate, as shown in Figure 8 to Figure 11. If the hot wire current was $30 \mathrm{~A}$, the temperature of hot wire was about $800^{\circ} \mathrm{C}$ during welding, which was lower than the temperature of the weld pool (around $900-1300^{\circ} \mathrm{C}$ ). On the other hand, if the hot wire current was $40 \mathrm{~A}$, the hot wire will have a temperature of around $1000{ }^{\circ} \mathrm{C}$, which was in the temperature range of the weld pool, causing the hot wire to melt homogeneously, making the workpiece stronger. Furthermore, it was found that the relationship between the cooling rate and tensile strength was inversely proportional; the workpiece with a lower cooling rate will be stronger than the fast cooling rate workpiece, as shown in Figure 15.

Table 7. Tensile strength results according to the experimental design.

\begin{tabular}{cccccc}
\hline Run Order & $\begin{array}{c}\text { A } \\
\text { (Wire Feed } \\
\text { Rate) } \\
(\mathbf{m} / \mathbf{m i n})\end{array}$ & $\begin{array}{c}\text { B } \\
\text { (Wire } \\
\text { Current)(A) }\end{array}$ & $\begin{array}{c}\text { Ultimate } \\
\text { Tensile } \\
\text { Strength } \\
\mathbf{( M P a )} \\
\text { Mean } \pm \text { SD }\end{array}$ & $\begin{array}{c}\text { Yield } \\
\text { Strength } \\
\mathbf{( M P a )} \\
\text { Mean } \pm \text { SD }\end{array}$ & $\begin{array}{c}\text { Elongation at } \\
\text { Break (\%) } \\
\text { Mean } \pm \text { SD }\end{array}$ \\
\hline $0^{*}$ & - & - & $598.52 \pm 0.91$ & $360.76 \pm 2.45$ & $35.36 \pm 0.06$ \\
1 & 1.7 & 40 & $607.23 \pm 7.42$ & $361.40 \pm 6.38$ & $30.60 \pm 5.98$ \\
2 & 1.7 & 30 & $515.22 \pm 142.81$ & $351.09 \pm 32.15$ & $17.63 \pm 20.62$ \\
3 & 1.5 & 40 & $610.95 \pm 2.76$ & $363.40 \pm 2.53$ & $30.28 \pm 3.56$ \\
4 & 1.5 & 30 & $428.70 \pm 61.45$ & $294.39 \pm 86.92$ & $4.78 \pm 1.99$ \\
\hline
\end{tabular}

* As-received material. 


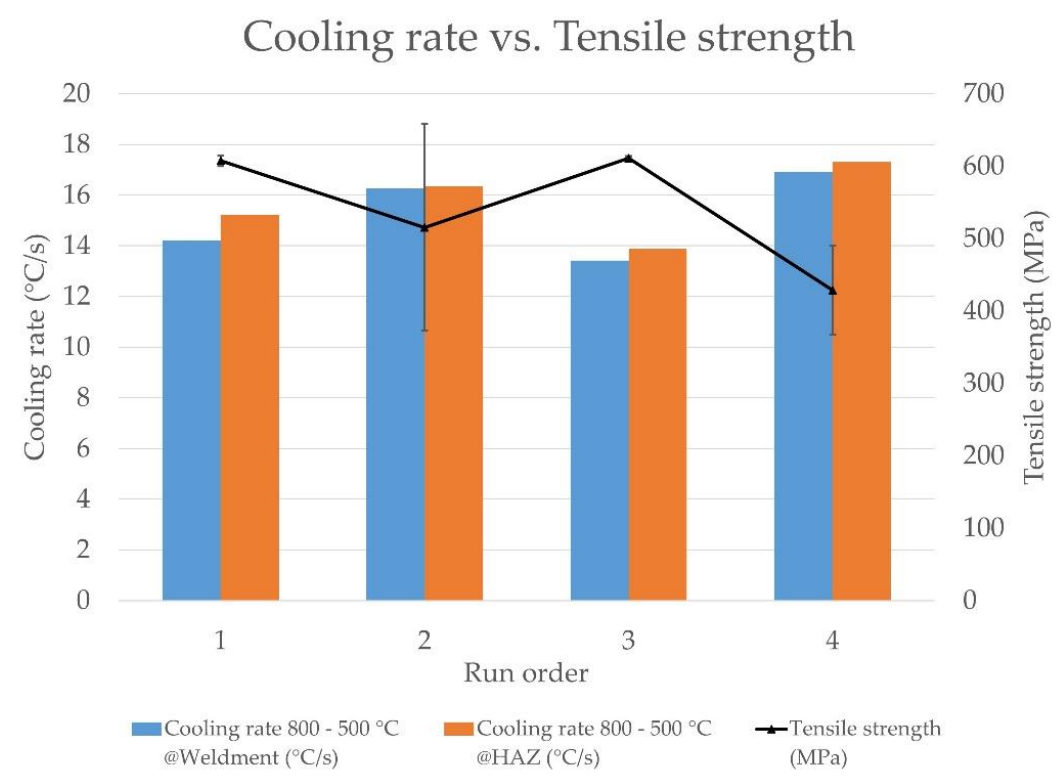

Figure 15. The relationship between cooling rate and tensile strength.

For Vickers microhardness values measured at each specified position shown in Figure 16, the microhardness characteristics were shaped like a " $\mathrm{W}$ ", with all the smallest microhardness values at the HAZ area that was away from the welding center line about $5 \mathrm{~mm}$, the measured microhardness was in the range of 180-210 HV, which was more than the standard microhardness of AISI 316 specified at $146 \mathrm{HV}$. It can be concluded that this parameter was suitable for use. The relationship between cooling rate and microhardness is shown in Figure 17. It was found that, if the cooling rate of $800-500^{\circ} \mathrm{C}$ was between 13 and $16^{\circ} \mathrm{C} / \mathrm{s}$, the microhardness will increase as the cooling rate increases. Although the cooling rate of $800-500{ }^{\circ} \mathrm{C}$ greater than $16^{\circ} \mathrm{C} / \mathrm{s}$ will result in a significant decrease in microhardness, the microhardness value is still higher than the standard value. However, the cooling rate was very important, thus the cooling rate of $800-500{ }^{\circ} \mathrm{C}$ should be controlled between 13 and $16^{\circ} \mathrm{C} / \mathrm{s}$ for the suitable results. Therefore, to control the cooling rate appropriately for this research, the hot wire current should be used at $40 \mathrm{~A}$ and the hot wire feed rate of $1.5 \mathrm{~m} / \mathrm{min}$ or $1.7 \mathrm{~m} / \mathrm{min}$ will give the most appropriate tensile strength and microhardness results.

Vickers Microhardness

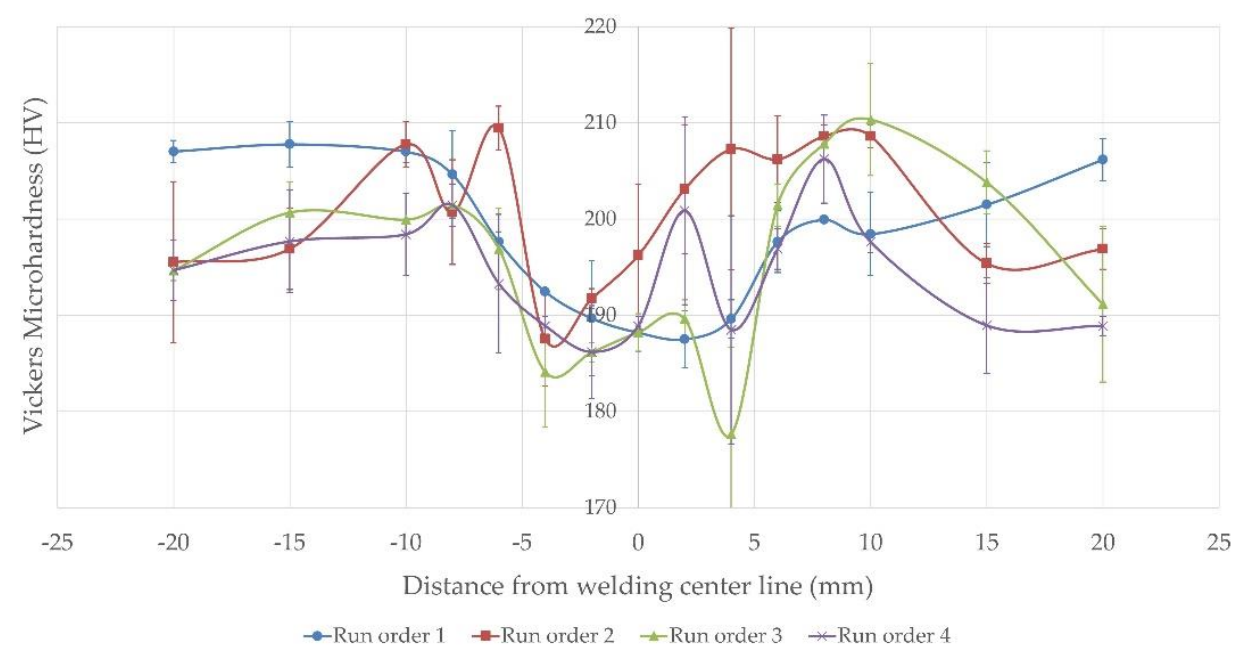

Figure 16. Vickers microhardness results according to the experimental design. 


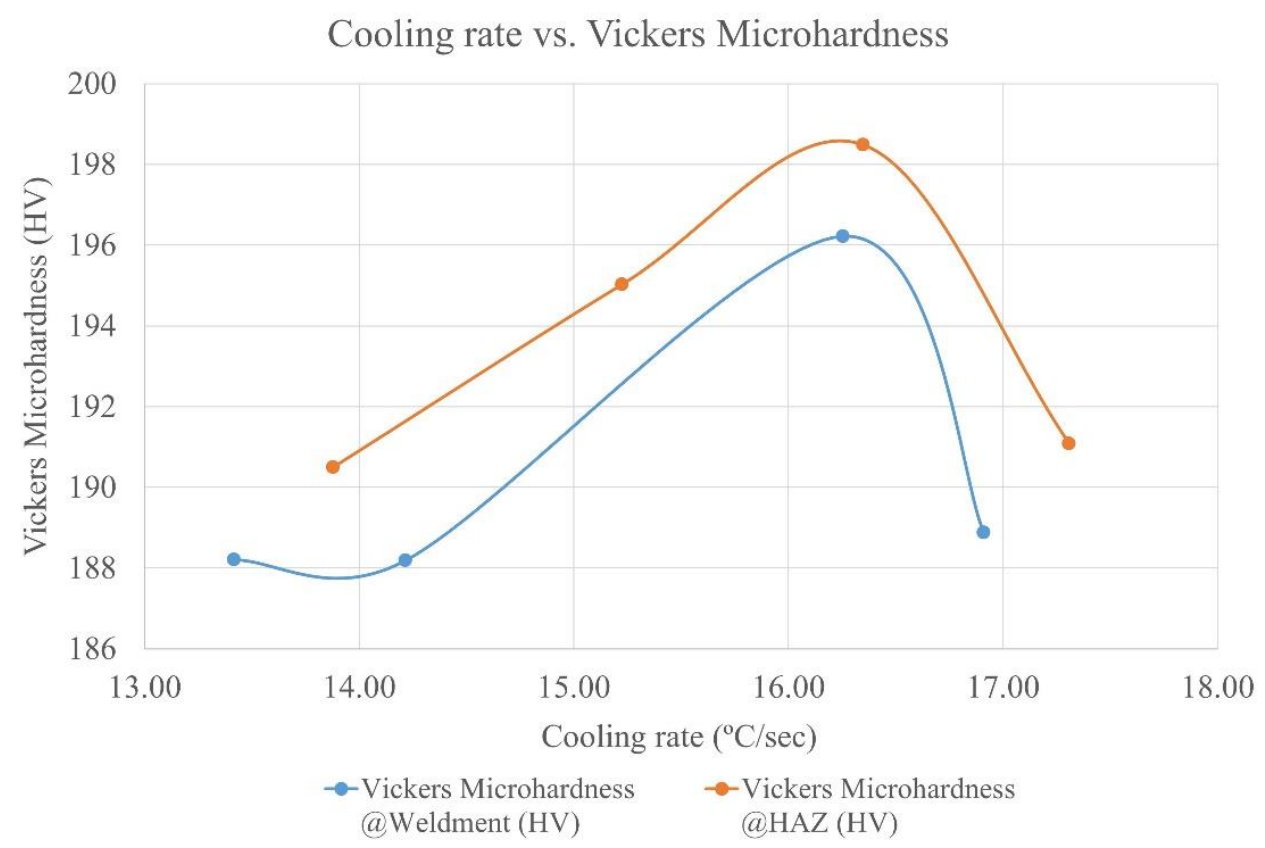

Figure 17. The relationship between cooling rate and Vickers microhardness.

\section{Conclusions}

This experiment can lead to the following conclusions:

1. The high-speed infrared thermography camera can record the temperature throughout the hot wire plasma arc welding process, allowing the maximum temperature to be known around $1300{ }^{\circ} \mathrm{C}$ and an " $\mathrm{M}$ " shaped graph form is generated. In the graph, the weld pool temperature is between 900 and $1300{ }^{\circ} \mathrm{C}$.

2. The factors studied by the hot wire current at $40 \mathrm{~A}$ will give the hot wire temperature around $1000^{\circ} \mathrm{C}$, which is the temperature in the weld pool range, causing the hot wire to melt homogeneous with the base material.

3. The cooling rate of $800-500{ }^{\circ} \mathrm{C}$ is between 13.42 to $17.31{ }^{\circ} \mathrm{C} / \mathrm{s}$, which affects the tensile strength, with the low cooling rate getting the maximum tensile strength at $610.95 \mathrm{MPa}$ and the tensile strength decreasing according to the high cooling rate. The cooling rate also affects the hardness, which should be controlled to between 13 and $16^{\circ} \mathrm{C} / \mathrm{s}$ to get the most suitable hardness. This cooling rate can be controlled by controlling the hot wire current.

4. The appropriate hot wire parameters are the hot wire current at $40 \mathrm{~A}$ and the wire feed rate of $1.5 \mathrm{~m} / \mathrm{min}$, which result in the workpiece having a cooling rate at $800-500{ }^{\circ} \mathrm{C}$ of $13.42{ }^{\circ} \mathrm{C} / \mathrm{s}$, tensile strength $610.95 \mathrm{MPa}$, and Vickers microhardness average at $195 \mathrm{HV}$-all such results are higher than standard materials values.

This study found that the hot wire current plays an important role in cooling rates and tensile strength. Therefore, the hot wire process parameters should be used appropriately to maximize the benefits of the hot wire plasma arc welding workpiece. In the future, the optimization of the hot wire process parameters will be performed to obtain the most suitable parameters and study the phenomena that affect the results. This manuscript only reports appropriate parameters of the hot wire process effects on tensile strength and microhardness.

Author Contributions: Conceptualization, N.N.; methodology, N.N.; data curation, J.N., W.P., and R.Y.; validation, N.N. and J.N.; writing — original draft preparation, N.N.; writing-review and editing, N.N.; supervision, N.N.; project administration, J.N. and W.P.; funding acquisition, N.N. All authors have read and agreed to the published version of the manuscript. 
Funding: This research received no external funding.

Acknowledgments: The authors would like to thank the National Metal and Materials Technology Center (MTEC), National Science and Technology Development Agency, Thailand for financial support.

Conflicts of Interest: The authors declare no conflict of interest.

\section{References}

1. Wen, P.; Cai, Z.; Feng, Z.; Wang, G. Microstructure and mechanical properties of hot wire laser clad layers for repairing precipitation hardening martensitic stainless steel. Opt. Laser Technol. 2015, 75, 207-213. [CrossRef]

2. Oliveira, J.P.; Crispim, B.; Zeng, Z.; Omori, T.; Fernandes, F.M.B.; Miranda, R.M. Microstructure and mechanical properties of gas tungsten arc welded $\mathrm{Cu}-\mathrm{Al}-\mathrm{Mn}$ shape memory alloy rods. J. Mater. Process. Technol. 2019, 271, 93-100. [CrossRef]

3. Oliveira, J.P.; Curado, T.M.; Zeng, Z.; Lopes, J.G.; Rossinyol, E.; Park, J.M.; Schell, N.; Fernandes, F.M.B.; Kim, H.S. Gas tungsten arc welding of as-rolled CrMnFeCoNi high entropy alloy. Mater. Des. 2020, 189, 108505. [CrossRef]

4. Hori, K.; Watanabe, H.; Myoga, T.; Kusano, K. Development of hot wire TIG welding methods using pulsed current to heat filler wire - research on pulse heated hot wire TIG welding processes. Weld. Int. 2004, 18, 456-468. [CrossRef]

5. Olivares, E.A.G.; Díaz, V.M.V. Study of the hot-wire TIG process with AISI-316L filler material, analysing the effect of magnetic arc blow on the dilution of the weld bead. Weld. Int. 2018, 32, 139-148. [CrossRef]

6. Bambach, M.; Sizova, I.; Silze, F.; Schnick, M. Comparison of laser metal deposition of Inconel 718 from powder, hot and cold wire. Procedia CIRP 2018, 74, 206-209. [CrossRef]

7. Pai, A.; Sogalad, I.; Basavarajappa, S.; Kumar, P. Results of tensile, hardness and bend tests of modified $9 \mathrm{Cr}$ 1Mo steel welds: Comparison between cold wire and hot wire gas tungsten arc welding (GTAW) processes. Int. J. Press. Vessel. Pip. 2019, 169, 125-141. [CrossRef]

8. Benyounis, K.Y.; Olabi, A.G.; Hashmi, M.S.J. Effect of laser welding parameters on the heat input and weld-bead profile. J. Mater. Process. Technol. 2005, 164, 978-985. [CrossRef]

9. Peng, W.; Jiguo, S.; Shiqing, Z.; Gang, W. Control of wire transfer behaviors in hot wire laser welding. Int. J. Adv. Manuf. Technol. 2016, 83, 2091-2100. [CrossRef]

10. Liu, W.; Ma, J.; Liu, S.; Kovacevic, R. Experimental and numerical investigation of laser hot wire welding. Int. J. Adv. Manuf. Technol. 2015, 78, 1485-1499. [CrossRef]

11. Zhou, Q.; Rong, Y.; Shao, X.; Jiang, P.; Gao, Z.; Cao, L. Optimization of laser brazing onto galvanized steel based on ensemble of metamodels. J. Intell. Manuf. 2018, 29, 1417-1431. [CrossRef]

12. Yang, Y.; Longchao, C.; Chaochao, W.; Qi, Z.; Ping, J. Multi-objective process parameters optimization of hot-wire laser welding using ensemble of metamodels and NSGA-II. Robot. Comput. Integr. Manuf. 2018, 53, 141-152. [CrossRef]

13. Li, J.; Sun, Q.; Kang, K.; Zhen, Z.; Liu, Y.; Feng, J. Process stability and parameters optimization of narrow-gap laser vertical welding with hot wire for thick stainless steel in nuclear power plant. Opt. Laser Technol. 2020, 123, 105921. [CrossRef]

14. Liu, W.; Liu, S.; Ma, J.; Kovacevic, R. Real-time monitoring of the laser hot-wire welding process. Opt. Laser Technol. 2014, 57, 66-76. [CrossRef]

15. Spaniol, E.; Ungethüm, T.; Trautmann, M.; Andrusch, K.; Hertel, M.; Füssel, U. Development of a novel TIG hot-wire process for wire and arc additive manufacturing. Weld. World 2020, 3, 1-12. [CrossRef]

16. Liu, X.F.; Jia, C.B.; Wua, C.S.; Zhang, G.K.; Gao, J.Q. Measurement of the keyhole entrance and topside weld pool geometries in keyhole plasma arc welding with dual CCD cameras. J. Mater. Process. Technol. 2017, 248, 39-48. [CrossRef]

17. Pinto-Lopera, J.E.; Motta, J.M.S.T.; Alfaro, S.C.A. Real-Time Measurement of Width and Height of Weld Beads in GMAW Processes. Sensors 2016, 16, 1500. [CrossRef]

18. Silwal, B.; Santangelo, M. Effect of vibration and hot-wire gas tungsten arc (GTA) on the geometric shape. J. Mater. Process. Technol. 2018, 251, 138-145. [CrossRef]

19. Wang, H. Effect of Welding Variables on Cooling Rate and Pitting Corrosion Resistance in Super Duplex Stainless Weldments. Mater. Trans. 2005, 46, 593-601. [CrossRef] 
20. Mohammed, G.R.; Ishak, M.; Aqida, S.N.; Abdulhadi, H.A. Effects of Heat Input on Microstructure, Corrosion and Mechanical Characteristics of Welded Austenitic and Duplex Stainless Steels: A Review. Metals 2017, 7, 39. [CrossRef]

21. Arora, A.; Roy, G.G.; DebRoy, T. Cooling rate in 800 to $500{ }^{\circ} \mathrm{C}$ range from dimensional analysis. Sci. Technol. Weld. Join. 2010, 15, 423-427. [CrossRef]

22. Poorhaydari, K.; Patchett, B.M.; Ivey, D.G. Estimation of Cooling Rate in the Welding of Plates with Intermediate Thickness. Weld. J. 2005, 10, 149-155.

23. 316 Stainless Steel, Annealed Sheet. Available online: http://www.matweb.com/ (accessed on 5 June 2020).

24. Thermography Theory. Available online: https://www.infratec.eu/thermography/service-support/ (accessed on 18 July 2020).

(C) 2020 by the authors. Licensee MDPI, Basel, Switzerland. This article is an open access article distributed under the terms and conditions of the Creative Commons Attribution (CC BY) license (http://creativecommons.org/licenses/by/4.0/). 